\title{
Modeling the Direction and Volume of Trade Flows in Global Crisis, COVID-19
}

\author{
Aayush Tyagi ${ }^{1}$ (D) Urmi Shah ${ }^{2}$
}

Received: 15 August 2020/Accepted: 3 February 2021/Published online: 17 February 2021

(C) The Institution of Engineers (India) 2021

\begin{abstract}
The massive spread of COVID-19 has disrupted trading activities worldwide plunging the economy of a nation; particularly, trade-dependent nations are severely affected by the restriction in exports and imports. This paper aims to evaluate the implications of COVID-19 on the trade economy of New Zealand by exploratory data analysis and ARIMA modeling. Based on a comprehensive strategy of analysis and prediction, data were processed to notice the impact of the pandemic on trade sales. ARIMA (Auto-Regressive Integrated Moving Average) model was implemented to assess and determine the total imports and exports value of New Zealand. The efficacy of the results was tested by employing standard error analytical techniques. Analysis of the results demonstrated that the trade economy of New Zealand shows plunge with the rise of pandemic and is likely to decline in future. On the basis, it is recommended that allowing trade for essential goods as a key factor in balancing the economy of trade in New Zealand. Future scope of the research is focused to identify other factors that could stimulate the economy of $\mathrm{New}$ Zealand during the pandemic.
\end{abstract}

Keywords COVID-19 · Data science - Analysis . Modeling $\cdot$ Economy $\cdot$ ARIMA

Aayush Tyagi

tyagiaayush5@gmail.com

Urmi Shah

urmi18shah@gmail.com

1 Department of Computer Science and Engineering, Graphic Era Deemed To Be University, Dehradun, Uttrakhand, India

2 Department of Computer Science and Engineering, Marwadi University, Rajkot, Gujarat, India

\section{Introduction}

The world economy has encountered numerous downfalls as a consequence of deadly pandemics since 1348 . However, a few numbers of pandemic and epidemic shook the financial system to its core. Black Death pandemic, surfaced in 1348, profoundly impacted the world economy by crashing at $29 \%$ in GDP while holding the history of maximum death rates. By 2002, an infectious respiratory disease (SARS) emerged, which influenced the decline of growth rate for over a year in most Asian countries, especially China, with its growth rate dropping down to 9.1\%. Witnessing coronavirus pandemic, Novel Coronavirus depicts a revolutionary toll on the international economy and trade. As an attempt to curb COVID-19, governments have declared the closure of borders, businesses, and factories. However, by such a bold resolution, the massive global trade of goods and services is restricted which disrupts the economy. Considering the damage caused by SARS-CoV-2, WTO compares present financial crisis with the economic crash of 2009. World trade is predicted to suffer a dramatic decline from 13 to 32 percent, says WTO.

Despite being geographically further from significant export markets, New Zealand stands 58th in the world for its export economy. Lacking certain goods, importing allows New Zealand to produce products locally by reducing its manufacturing costs. On the other hand, exporting boosts New Zealand's revenues and profits and, as a result, the national economy. Presently, international trade is contributing as much as $60 \%$ of New Zealand's total economic activity. Asian countries play a huge role in New Zealand's imports as 53\% of the country's imports are purchased by countries in Asia. The largest import categories in New Zealand, including machinery (which 
includes computers) and vehicles, contribute two-thirds of the total product acquisition value.

Regarding the export, New Zealand shipped goods of 18.9 billion dollars in the first six months of 2020. Mainly exporting food products (which includes dairy, meat, and fish), New Zealand's exports are accounted for $75 \%$ of its overall worldwide purchases. Countries such as India, New Zealand, China, the UK, and many more are on the verge of collapse due to the shutdown of international trade business. Regarding elevated unemployment and revenue, various countries have tools and mechanisms which can be used in response to minimize the loss [1]. The present study attempts to assess the impact of the corona pandemic on New Zealand trade by performing exploratory data analysis and applying ARIMA modeling.

The rise of COVID-19 has impacted various aspects of the global economy, especially trading goods from one country to another. Several studies have shed light on the analysis of trade among numerous countries. While there has been much research on investigating the trade economy amid the coronavirus pandemic, few researchers have emphasized predicting trade economy.

The relation between pandemic and economic crisis is well established; research by Arun and Ozili [2] concluded that an increase in the number of coronavirus-infected patients did not have a notable influence on the economy, and only the new policies established due to the spread of the virus rigorously changed the face of economic activities. However, the lack of a rich dataset and resemblance to a similar financial crisis makes the overall findings limited to defined criteria of observations.

The authors of [3] analyzed the price data of stock markets and suggested the forecast of stock markets using the forecasting model, LBL-LSTM. On comparing the current economic downfall with the financial crisis during the SARS outbreak, the researchers established representations of the stock chart in both periods, along with prediction performance indicated using RMSE. The distinctness of this study is the active and adjustable model used to train and predict the data collected from Yahoo Finance Message Board.

A study by McKibbin and Fernando depicts the resemblance between the global crisis, which took place in 2008-2009, and the current economic crisis [4]. The international trade collapse in 2008 surfaced due to demand-side shock, a sudden drop in the demand of goods or services, along with a supply-side shock from the finance sectors. Research shows it is dubious to expect the current trade to collapse as hard.

Several empirical studies have focused on examining the adverse effect on trade volume amid the pandemic $[5,6]$, while a systematic review by Farooqi offers forecasts for annual import/export flow in Pakistan using the ARIMA model [7]. While the researcher inspected the results on as many as ten tentative ARIMA models, he reflects on the limitation of the method being suitable for at least fifty observations. Similarly, authors of [8] compare different time-series models with ARIMA and conclude the trendy method, ARIMA, performs well for a real-world timeseries forecast and analysis.

Nonetheless, there is a lack of robust research on the impact of COVID-19 on analyzing trade flow impact in New Zealand. This research paper intends to bridge this gap by providing a detailed exploratory analysis using ARIMA modeling to investigate the effect of COVID-19 on the annual trade flow in New Zealand.

\section{Rise of COVID-19}

In December, a month later, after the first outbreak of the coronavirus in China, WHO declared the virus to be a public health emergency [9]. Despite early signs of COVID-19 in China and other Asian countries, the first case of coronavirus surfaced in New Zealand three months later than in China [10]. Despite having zero coronavirus cases for a month, the New Zealand government allowed only New Zealand citizens to enter the country. The spread of coronavirus was declared a pandemic soon after the virus's uncontrollable expansion in more than 18 countries worldwide [11]. New Zealand imposed a complete shutdown by March with only one active case, when countries like China and England experienced a total number of 80,304 and 16,000 coronavirus-infected patients. New Zealand reported the first appearance of coronavirus in August, after 100 days of being corona-free. Meanwhile, Australia and England continued showing a downward trend in fatalities and confirmed cases concerning the SARS-CoV-2. Figure 1 displays the intensity of the coronavirus spread worldwide, including the maximum number of deaths and confirmed cases of the virus.

\section{Impact on Trade Sales}

The economy of New Zealand is considered trade-dependent, and as a result, one of the open market economies in the whole world. As mentioned by New Zealand Foreign Affairs and Trade, 70 to 95 percent of the country heavily relies on the export of the vital primary sectors (meat, dairy, seafood, wine, and forestry) [12]. Because of the low domestic market, the rise in export sales is essential as international trade is responsible for 6 out of every ten jobs in New Zealand [13]. Along with export, imported products such as cars and machinery equipment contribute to New Zealand's high GDP. When the goods had been exported earlier, they are imported to the same country which is 

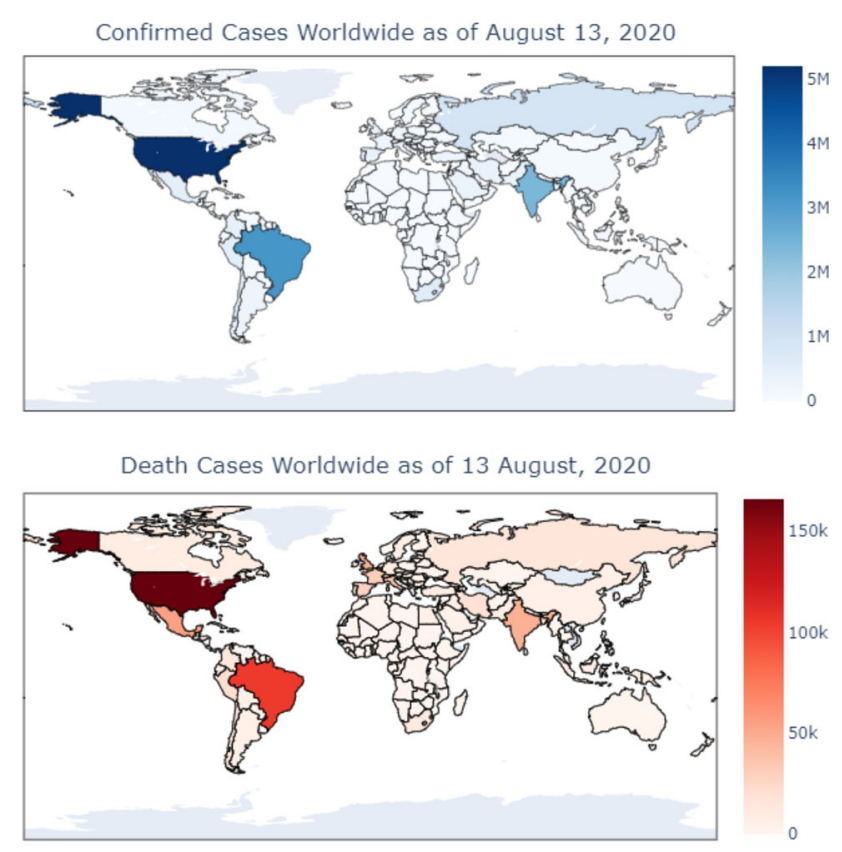

Fig. 1 COVID-19 worldwide confirmed cases and deaths

called reimportation. It is noteworthy to discern that reimportation provides a negligible input to the country's trade sales. Figure 2 provides insight into the total earnings obtained from trade (export/ import/ reimport) from February to July 2020. China, one of the giant patrons of New Zealand concerning export and imports, issued a halt on trading business in 2019, which initiated a sparse reduction in sales. The majority of other countries witnessed the expansion of SARS-CoV-2 in early 2020 and implemented temporary closure to the international trades. It explains the sinking trade sales value in New Zealand after the spread of COVID-19 in various countries.

By taking into account major transportation modes for exporting and importing, New Zealand's trade underwent a

Total value obtained from Exports/Imports over the months

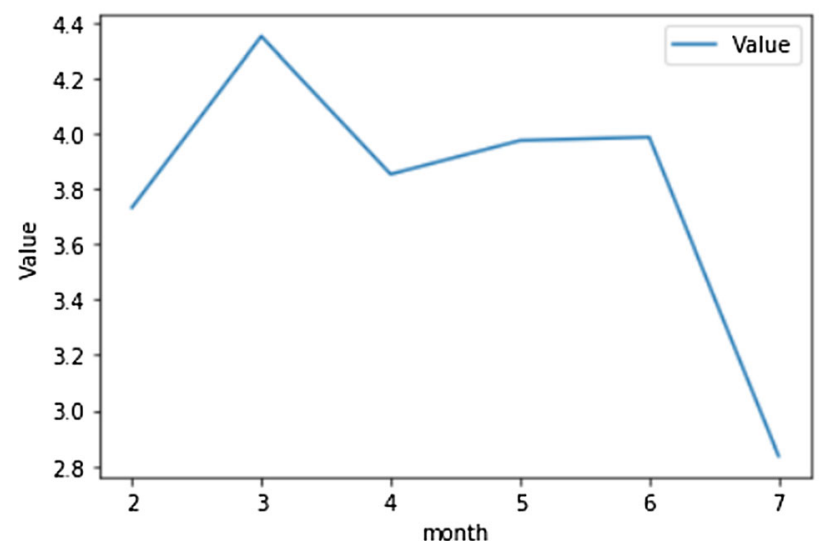

Fig. 2 Value obtained from export/import/reimport over the month decline in sales. While the values showed growth in March 2020, the drop in sales in the following months cannot be ignored.

\section{Export Flow}

New Zealand is responsible for the exportation of the highest values of goods to China. The sudden plunge of reduction in the exportation to China is noticeable in Fig. 3, which is a repercussion of the initial lockdown implementation in China. Unlike in China, Australia did not implement immediate strict restrictions though imposed international travel and trading restrictions gradually. Imports in Australia, such as agricultural chemicals and ingredients, encountered a disruption and had to rely on the local suppliers to curb the damage [14] which explains the vague decrease in the value of exports to Australia. The American and Japanese governments placed no restrictions on international trading whatsoever, which distinctly justifies the raise of income from exports to Japan accompanied by the fragile extension in the value of goods exported to the USA, as shown in Fig. 3. All the countries in East Asia, excluding China, play the second-highest role for the maximum value of goods exported from New Zealand. Most East Asian countries like Japan and North Korea did not place international trade ban restrictions, allowing New Zealand to continue export goods for a significantly higher rate. New Zealand underwent a considerably lesser downfall of the export value for the European Union, and in the case of the UK, New Zealand did not have a substantial consequence in the prices of the export goods.

\section{Export Direction and Commodity Relation}

According to the World Bank, disruption to the agricultural inputs imposes a more prominent risk for food insecurity

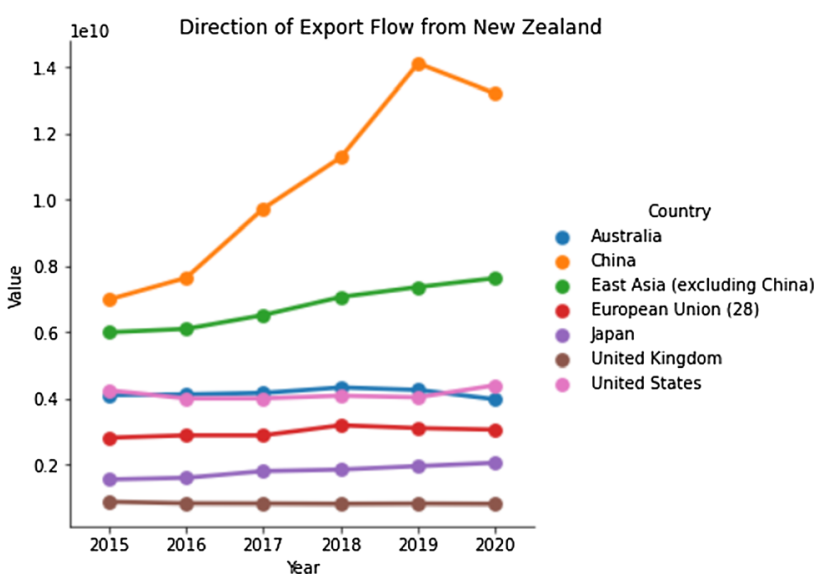

Fig. 3 Export flow 
by jeopardizing next season's crop without necessary pieces of equipment such as fertilizers and seeds [15]. In such circumstances, people prioritize stocking adequate food to survive any incoming crisis. New Zealand noticed a majority of the people engaged in panic buying, despite the government's declaration of having a satisfactory amount of food stock. A visible effect of the COVID-19 restrictions can be recognized on the exports of essential commodities (food and forestry), as depicted in Fig. 4. It is needless to say that exportation in fruit and dairy has shown intensification, among dairy being the most leading, followed by fruit and meat. In spite of the fact that the value of fruit export had been escalating since 2017, the exportation in fruit commodity experienced a sudden surge of increase from the year 2019 and rising forward over the year 2020. Considering the dairy export, at the end of 2016, the dramatic growth of price is visible; however, the prices shoot straight up with the increase in the spread of the COVID19. While dairy and fruit export value rose significantly, the numbers for meat export remained steady despite the pandemic. It is also noteworthy to notice the downfall of seafood exports followed by 2019. Forestry, New Zealand's one of the influential exports, has shown a drastic sharp drop, sternly affecting the economy of New Zealand. The stats NZ spokesman Darren Allan has shared his viewpoints on the trade crisis by emphasizing to take cautionary decisions in the import and export of various commodities.

\section{Experimental Results}

ARIMA model excludes assuming financial model knowledge unlike other time-series models. It solely considers the forecasting based on the past values and errors considered [16]. One of the key benefits of using ARIMA is its better performance than most models for predicting

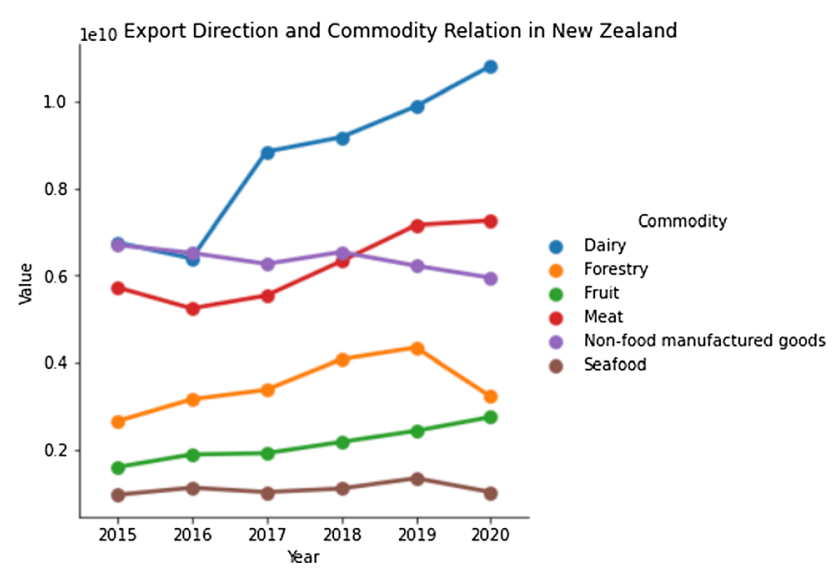

Fig. 4 Direction and commodity relation comprehensive time-series data while being less susceptible to data fluctuations [17]. As compared to ARIMA, multivariate models cause a problem regarding the data timeliness resulting in forecast uncertainty. With time, several studies [18] have established ARIMA models' success in outperforming sophisticated models with regard to forecasting data.

Figure 5 illustrates a general modeling and prediction strategy using the ARIMA model. The flowchart does not follow a succeeding pattern and includes iterative loops wherever required. The process starts with collecting the time-series data, followed by examining and processing the dataset to obtain a noteworthy analysis of the trade flow. The stationary or non-stationary state of the time-series data is tested in the third step of the process, where an iterative loop will direct the data to be transformed into stationary state of data. Once the stationary time-series data is achieved, the consequent and most critical step requires to identify the best fit line of the ARIMA model to estimate the correct results. After successfully completing the fourth step, the model is used to perform the prediction of the

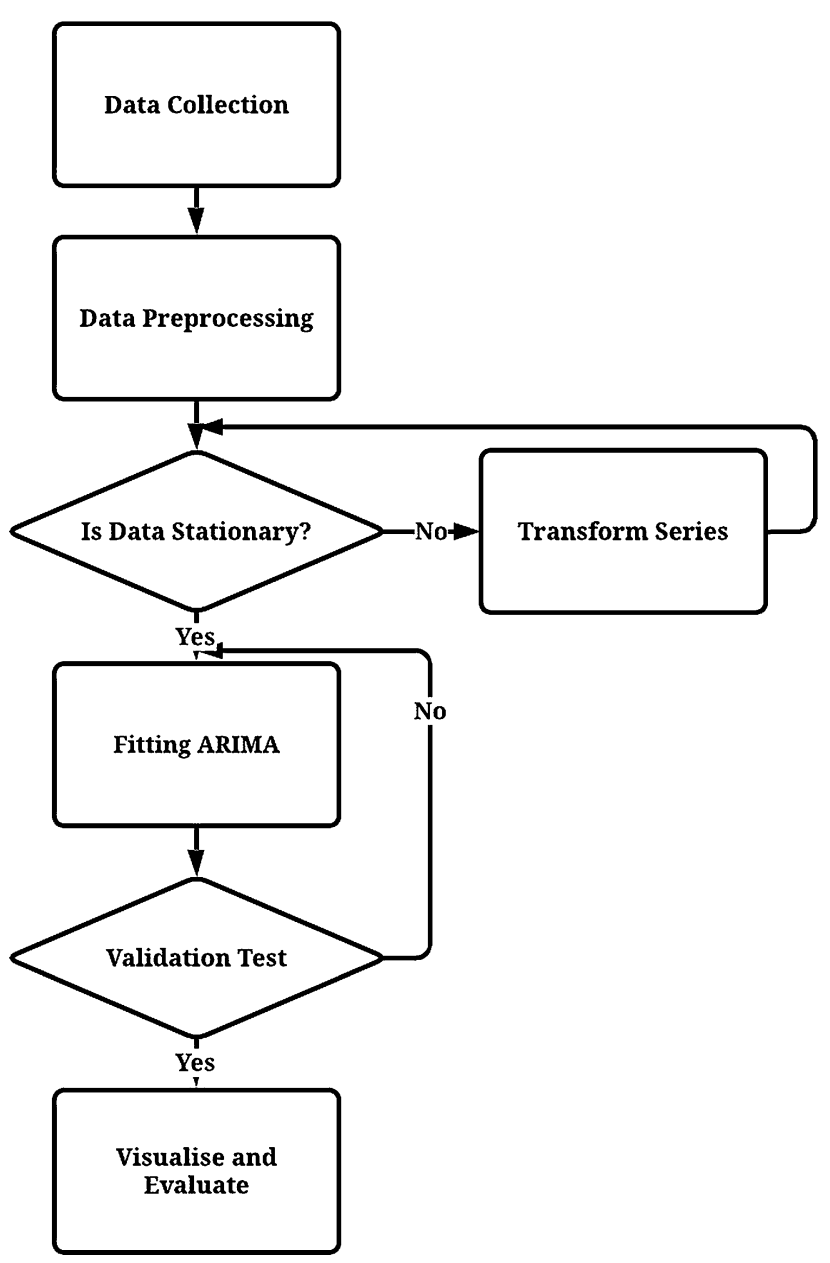

Fig.5 Process flow 
time-series data, which will allow further evaluation of the prediction results.

The summary statistics for the trading imports, exports, and reimports of New Zealand are shown in Table 1,

For conducting the experimental analysis, firstly, the data have to be examined and analyzed, followed by testing the data to obtain its stationary state. Figure 6 illustrates the filtered export and import records obtained by normalizing significant features of the time-series data using Min-Max normalization. After performing normalization with Min-Max, the minimum and maximum value gets converted to 0 and 1 , respectively.

Before carrying forward with the model application, the state of data should be stationary. Stationary data resemble that its statistical properties remain steady over time, which makes it easier for the model to perform an errorless forecast. ADF test (augment Dickey-Fuller test) provides the null hypothesis of the given time-series data [19]. The AdFuller function is required to identify the need for difference; a method to transform non-stationary time series into stationary, where $\mathrm{d}=0$ relates to differencing, is unneeded. Figure 6 signifies the PACF plot representing the partial correlation coefficients among the time-series data and lags of itself with respect to the partial autocorrelation function (PACF). Considering the presence of unit root by the null hypothesis, the value of $\mathrm{p}$ should be less than 0.05 , inferring the stationary state of the time-series data. The graph plot, given in Fig. 7, yields the p degree value equal to 9 and the value of degree $q$ equal to 1 . It provides satisfactory conditions to apply the ARIMA model as shown in Fig. 8 allow to evaluate the import and export trade values predicted using the ARIMA model.

This model is evaluated based on four vital metrics,

$\operatorname{MSE}=\frac{1}{n} \sum_{i=1}^{n}\left(Y_{i}-\hat{Y}_{i}\right)^{2}$

MSE (mean square error) denotes the average of squared errors

MAE $=\frac{\sum_{i=1}^{n}\left|Y_{i}-\widehat{Y}_{i}\right|}{n}$

Unlike MSE, mean absolute error (MAE) measures the
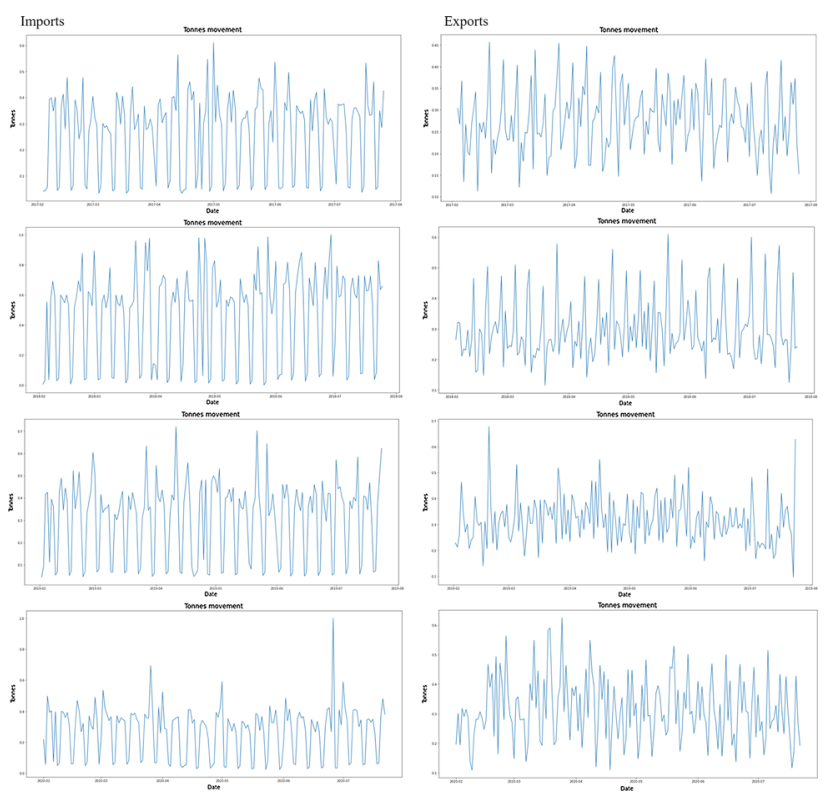

Fig. 6 Amount of tonnes involved in export and import over the years

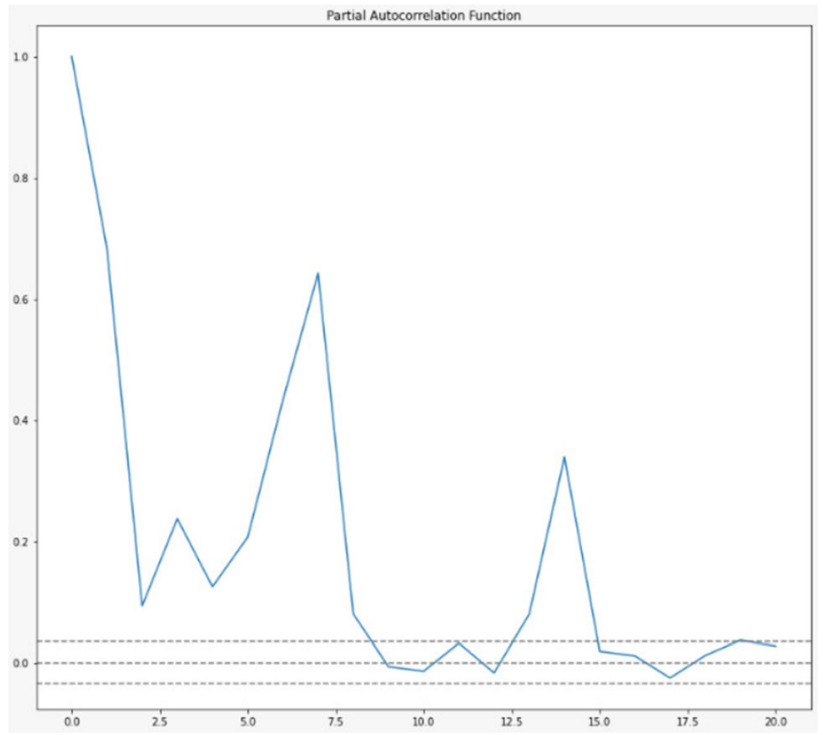

Fig. 7 Partial autocorrelation function for trade dataset over the years

square of the average distance between real and predicted data [20]

Table 1 Statistics for the trading imports, exports, and reimports of New Zealand

\begin{tabular}{llr}
\hline Direction & Mean & Standard deviation \\
\hline Exports & $2.464 \mathrm{e}+07$ & $4.499+07$ \\
Imports & $5.622 \mathrm{e}+07$ & $6.889 \mathrm{e}+07$ \\
Reimports & $4.972 \mathrm{e}+05$ & $7.770 \mathrm{e}+05$ \\
\hline
\end{tabular}



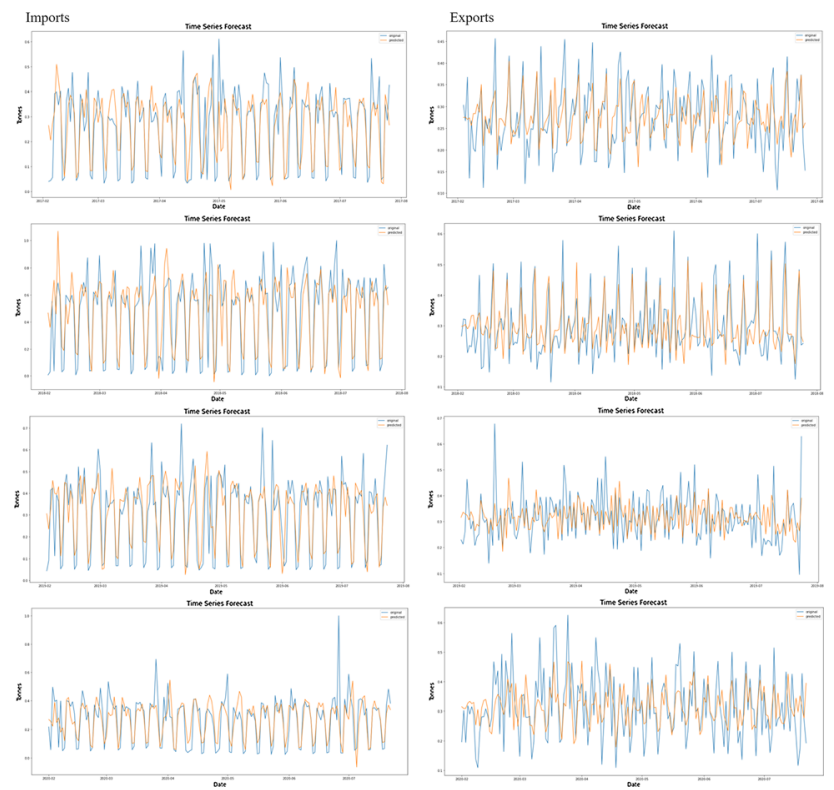

Fig. 8 Prediction versus original values for export and import over the years

$\mathrm{RMSE}=\sqrt{\frac{1}{x}} \sum_{i} n_{i}^{2}$

RMSE (root-mean-squared error) primarily denotes the concentration of the data around the best fit line, where $n$ equals the number of data points in the provided timeseries data and $\mathrm{x}$ denotes number of measurements, along with Yi and $\hat{Y}_{i}$ denoting observed and predicted values. Table 2 presents notable evaluation error metrics.

After data normalization using Min-Max and dropping irrelevant features from the time-series data, import records undergo filtration as shown in Fig. 9. It is significant to note the ADF function displays the data to be non-stationary considering the test statistics is larger than the critical values.

It requires the process of differencing in order to decrease the value of and make the data stationary. After applying the autocorrelation function (ACF) and partial autocorrelation function (PACF), the $\mathrm{p}$ and $\mathrm{q}$ values are equal to 1 denoting the null value of differencing. Once the model is built, its assessment is based on the value of metric errors.

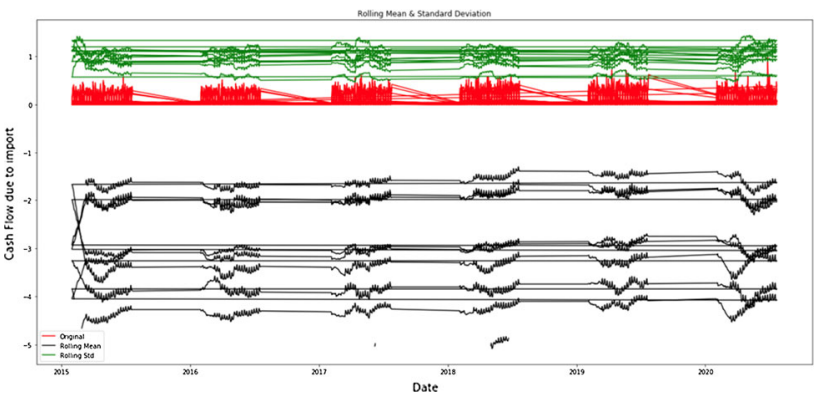

Fig. 9 Rolling mean and standard deviation

In order to fit the ARIMA model, the irrelevant features in the reimports data are dropped followed by normalization. Once again, the AdFuller function depicts a non-stationary state of the data. Therefore, the $\mathrm{p}$ and $\mathrm{q}$ values are transformed into 1 with differencing. ARIMA model is later applied to the features as shown in Fig. 10.

\section{Conclusion}

The research aims to evaluate the consequences of the trade economy in New Zealand caused by the coronavirus pandemic by using the ARIMA model. This research has provided the following accomplishments:

After March, when most countries declared a complete shutdown of import and export, the trade value analysis for New Zealand starts descending.

Considerable shortage of export values faced by New Zealand to countries such as Australia, China, East Asia, European Union, Japan, the UK, and the USA after the first few months of 2020

The sinking value of all commodities except food products, such as dairy, fruit, and meat, during the emergence of COVID-19

Performed data analysis, data normalization, and transformation to fit the ARIMA model

Conducted error metric evaluation after implementing the ARIMA model to stationary time-series data

Although the results are quite favorable for the given time-series data, the gap may have resulted from ARIMA's backwards-looking approach for predicting turning points.

Table 2 Error metrics

\begin{tabular}{llll}
\hline Metrics & Import & Export & Reimport \\
\hline MSE & 0.00605 & 0.00125 & $1.85 \mathrm{E}-06$ \\
RMSE & 0.15906 & 0.12256 & 0.001425 \\
MAE & 0.11419 & 0.76281 & 0.00108 \\
\hline
\end{tabular}




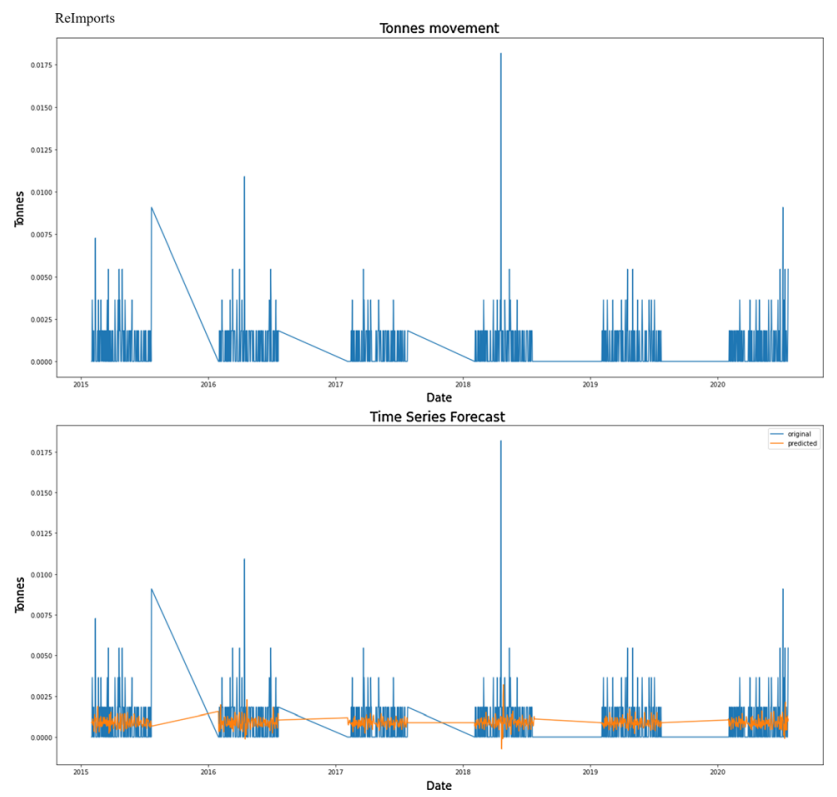

Fig. 10 Prediction versus original values for reimports data

The results present a better comprehension of the trade impact on New Zealand concerning the coronavirus pandemic. The demand for essential goods in New Zealand is likely to elevate in the following months, while that for non-essential goods will continue to plummet. The policymakers could prioritize to keep the worldwide supply chains active by trading essential goods, such as food products and medical supplies. The restriction of export trade on fundamental goods puts the international trade market at risk and can accelerate panic buying, consequently increasing difficulties for trade-dependent countries like New Zealand. This paper has one prominent limitation of restricted analysis due to the confined dataset. A more extended dataset with a longer period may capture the economic consequences of financial management amid the coronavirus pandemic. Furthermore, this paper can be developed in the future by applying the ARIMA model to a noiseless variant of the trade data series. This could be done using advanced statistical techniques and decrease the random fluctuations of noise.

\section{References}

1. M. Maliszewska, A. Mattoo, D. van der Mensbrugghe, The potential impact of COVID-19 on GDP and trade : a preliminary assessment. policy research working paper; No. 9211. World Bank, Washington, DC. (C) World Bank. (2020). https://openknowledge.worldbank.org/handle/10986/33605 License: CC BY 3.0 IGO.

2. P. Ozili, T. Arun, Spillover of COVID-19: impact on the global economy. SSRN Electro J https://doi.org/10.2139/ssrn.3562570
3. U. Gurav, S. Kotrappa, Impact of COVID-19 on stock market performance using efficient and predictive LBL-LSTM based mathematical model. Int. J. Emerg. Tech. 11(4), 108-115(2020). Available at SSRN: https://ssrn.com/abstract $=3670565$

4. W.J. McKibbin, R. Fernando, The global macroeconomic impacts of COVID-19: seven scenarios (March 2, 2020). CAMA Working Paper No. 19/2020, (2020). https://doi.org/10.2139/ssrn.3547729

5. M. Jinjin. Research on the impact of COVID19 on global economyiop conference series. Earth Environ. Sci. 546, 032043. (2020)

6. S.C. Gherghina, D.S Armeanu, C.C. Joldes, Stock market reactions to COVID-19 pandemic outbreak: quantitative evidence from ardl bounds tests and granger causality analysis. Int J Environ Res Public health 17(18), 6729 (2020). https://doi.org/10.3390/ijerph17186729

7. A. Farooqi, ARIMA model building and forecasting on imports and exports of Pakistan. Pakistan J. Stat. Oper. Res. 10, 157. (2014). https://doi.org/10.18187/pjsor.v10i2.732.

8. Z.A. Farhath, B. Arputhamary, D.L. Arockiam, A survey on Arima forecasting using time series model. (2016)

9. C. Sohrabi, Z. Alsafi, N. O'Neill et al., World Health Organization declares global emergency: a review of the 2019 novel coronavirus (COVID-19) [published correction appears in Int J Surg. 2020 May;77:217]. Int. J. Surg. 76:71-76. (2020). doi: https://doi.org/10.1016/j.ijsu.2020.02.034

10. S. Chaturvedi, COVID-19 pandemic: are we witnessing the first world war?. Indian J. Public Health [serial online]. Cited Aug 15 2020. (2020). http://www.ijph.in/text.asp?2020/64/2/99/286817

11. A. Spinelli, G. Pellino, COVID-19 pandemic: perspectives on an unfolding crisis. $\mathrm{Br} \quad \mathrm{J}$ Surg. 107(7), 785-787 (2020). https://doi.org/10.1002/bjs.11627

12. A. Bollard, Globalisation in the time of coronavirus. Policy Q. [S.1.], 16(3), ISSN 2324-1101 (2020). doi: https://doi.org/ https://doi.org/10.26686/pq.v16i3.6549.

13. P. Walsh, Trade unions in New Zealand and economic restructuring, (ACIRRT, Sydney, 1991). http://hdl.handle.net/2123/12352

14. T. Guerin, Ploughing on: supply chains in agriculture in the COVID-19 era [online]. Governance Dir. 72(5), 245-249 (2020). Availability:

https://search.informit.com.au/

documentSummary; $\mathrm{dn}=262259089085617$;res=IELBUS ISSN: 2203-4749. cited 15 Aug 20

15. [PETETIN, L. , The COVID-19 crisis: an opportunity to integrate food democracy into post-pandemic food systems. Eur J Risk Regul 11(2), 326-336 (2020). https://doi.org/10.1017/err.2020.40

16. M. Psychalis, Int Rev Econ Financ 69, 678-679 (2020). https://doi.org/10.1016/j.iref.2020.06.036

17. S. Siami-Namini, N. Tavakoli, A. Siami Namin, in 2018 17th IEEE International Conference on Machine Learning and Applications, A comparison of ARIMA and LSTM in forecasting time series. (ICMLA) (Orlando, FL, 2018), pp. 1394-1401, doi: https://doi.org/10.1109/ICMLA.2018.00227.

18. D. Stockton, J. Glassman, An evaluation of the forecast performance of alternative models of inflation. Rev. Econ. Stat. 69(1), 108-117 (1987)

19. R. Mushtaq, Augmented dickey fuller test. SSRN Electron J (2011). https://doi.org/10.2139/ssrn.1911068

20. A. Botchkarev, Performance metrics (Error Measures) in machine learning regression, Forecasting and prognostics: properties and typology. ArXiv, abs/1809.03006. (2018)

Publisher's Note Springer Nature remains neutral with regard to jurisdictional claims in published maps and institutional affiliations. 